Chirurgia (2020) 115: 792-797

No. 6, November - December

Copyright@ Celsius

http://dx.doi.org/10.21614/chirurgia.115.6.792

\title{
Percutaneous Retroperitoneoscopic Drainage of Complex Extraperitoneal Abscesses Using Flexible Endoscopy: Description of Technique and Perioperative Care
}

\author{
Charalampos Seretis*, Fotios Seretis, Shuker Yahia, Jagjit Gill, Adnan Malik, Kassim Zayyan
}

Department of General Surgery, George Eliot Hospital NHS Trust, Warwikshire, United Kingdom

*Corresponding author:

Charalampos Seretis, MD

Specialty Registrar in General Surgery,

George Eliot Hospital NHS Trust.

College Street, Nuneaton, CV10 7DJ

United Kingdom.

E-mail: babismed@gmail.com

\section{Rezumat}

Drenajul percutanat retroperitoneoscopic al abceselor extraperitoneale complexe prin endoscopie cu tub flexibil: descrierea tehnicii chirurgicale și a pregătirii preoperatorii

Tratamentul abceselor de psoas primare se efectuează, de regulă, printr-o combinație de terapie cu antibiotic de lungă durată şi drenaj cu tehnici radiologico-chirurgicale. Totuşi, deşi această combinatie este, de regulă, adecvată în tratamentul abceselor colectate extraperitoneale solitare, prezența abceselor complexe cu localizare multiplă necesită, de regulă, proceduri multiple şi, adesea, intervenții chirurgicale deschise. Vom descrie în continuare o tehnică alternativă de drenaj percutanat retroperitoneoscopic pentru abcese primare multiple de psoas extinse prin endoscopie cu tub flexibil, care permite tratamentul acestor cazuri printr-o intervenție unică, minim invazivă.

Cuvinte cheie: drenaj percutanat retroperitoneoscopic, abcese extraperitoneale, endoscopie cu tub flexibil

\section{Abstract}

The treatment of primary psoas abscesses usually is performed by a combination of prolongued antiobiotic therapy and drainage with interventional radiology techniques. However, although this combination is usually adequate for the treatment of solitary extraperitoneal collections, the presence of multi-loculated 
complex abscesses requires usually multiple procedures and feruently mandates open surgery. Herein, we describe an alternative tehnique of percutaneous retroperitoneoscopic drainage of multiple extensive primary psoas abscesses using flexible endoscopy, which can enable treatment these cases as one-stop proedure in a minimally invasive manner.

Key words: percutaneous retroperitoneoscopic drainage, extraperitoneal abscesses, flexible endoscopy

\section{Introduction}

Primary psoas abscesses represent a rare clinical entity, manifestating with a plead of symptoms, making clinical daignosis very difficult without appropriate imaging (1). The traditonal treatment of these patients consists of a combination of extended antimibriobial therapy based on the obtained pus/blood cultures with ad hoc drainage of the formed collections by interventional radiology means, depending on their size and location $(2,3)$. Upon failure of the above-mentioned strategy and/or in cases of multilocualted collections, open surgery has until recently been considered as the most frequent therapeutic option $(4,5)$.

In addition to the above-mentioned techniques, there are few reports describing the use of a percutaneous retroperitoneoscopic approach to enable drainage of these abscesses, utilising equipment which is used in standrad laparoscopic procedures, such as laparoscopic ports and trocars, as well as standard or angled laparosopes $(6,7)$. This technique aims to enable a degree of visualisation of the abscess track and cavity and allows direct lavage and placement of drains, adding to the overall value of its minimally invasive nature. The main drawbck of this technique though is the inability to completely inspect the collection cavities, as well as it hinders difficulties in ascertaing fistulation to adjacent structures and perfrom endoscopic-assisted drainage and lavage in cases of multiloculated collactions, all secondary to the restrictions imposed by the rigidity of the standard laparosope. In our case, where we encounered multiple and extensive extraperitoneal psoas abscesses, we present a modification of the abovementioned percutaneous retroperitoneoscopic approach, utilising a $5 \mathrm{~mm}$ flexible endoscope instead of a rigid standard laparoscope to direct our intervention.

\section{Case Presentation}

A 68-year old Cauasian female with no prior medical or surgical history of note was admitted to our Accident and Emergency Service with low-grade pyrexia and palpable massess in the left lower quadrant of her addomen, as well as her left flank. She denied any recent changes in her bowel habits, involuntary weight loss or gastrointestinal bleeding, as well as history of focal trauma. Her admission inflammatory markers were elevated, with a C-reactive proteine (CRP) value of $193 \mathrm{mg} / \mathrm{L}$ (reference values 0-11 $\mathrm{mg} / \mathrm{L}$ ) and a total white cell count (WCC) of 16.8 $\mathrm{x} 10^{9} / \mathrm{L}$ (reference values: $4-11 \times 10^{9} / \mathrm{L}$ ). Given the overall presentation, we proceeded with a computed tomography (CT) scan of her abdomen and pelvis, which revealed the presence of multiple sizeable multicolucated extraperitoneal abscesses on the left side, with one large collection in the left iliac fossa and left lumbar region, and another bilobar collection posteriorly to the left kidney, which had been displaced in a more anterior location (Fig. 1). No obvious communication was seen on the CT scan with the adjacent colon or the tail of the pancreas. At that stage, and since the patient has very stable haemodynamically, she was commenced on intravenous empeirical antibiotics after consult with our microbiologists (meropenem 1 gram $\mathrm{BD}$ and clindamycin 


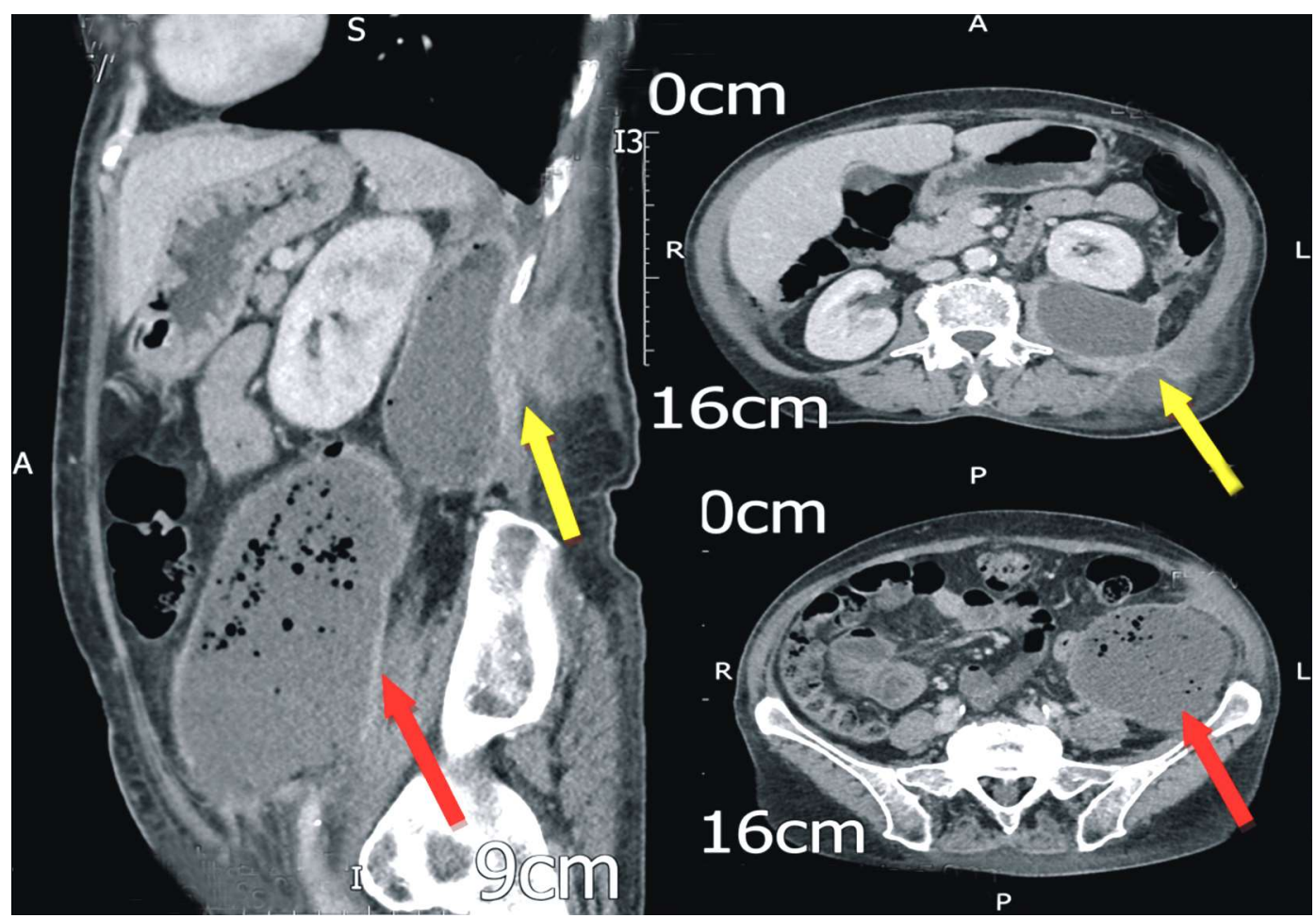

Figure 1. Admission CT scan, demonstarting two large extraperitoneal collections, one adjacent to the left psoas musle (red arrows) and a second extending posteriorly to the left kidney and fisulating towards the subcuticular space (yellow arrows)

450mg QDS) and a bedside aspiration of the left iliac fossa collection was performed under sterile conditions, in order to obtain a sample for microbiolgy culture and subsequent antibiogram. After discussion of the case with our interventional radiologists, we arrannged a CT-guided drainage of the most dependant left iliac fossal collection, which was performed uneventfully with insertion of a $12 \mathrm{~F}$ pigtail drain; a second sample of pus was sent for microbilogical analysis. Unfortunately, after four days on of continuous free drainage, a repeat $\mathrm{CT}$ scan revealed the persistence of all collections, with moderate only reduction in their volume (Fig. 2). At that stage, we decided to proceed with percutaneous retroperitoneoscopic drainage of these collections under general anaesthesia for definitive control of the source of infetion.

\section{Surgical Technique}

The patient was positioned in supine position with the left side elevated at 30

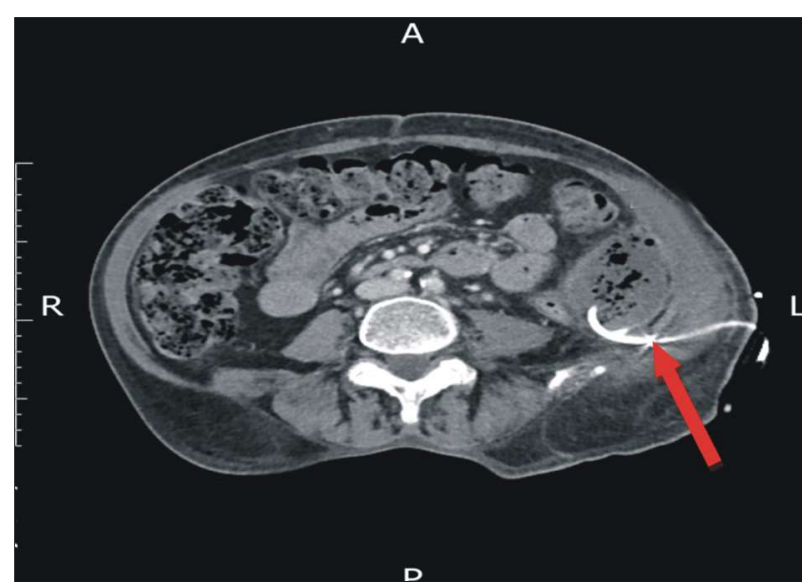

Figure 2. CT scan obtained after the insertion of a percutneous pigtail drain in the inferior collection adjacent to the left psoas muscle (red arrow) by our interventional radiology team; note the partial only resolution of the collection 
degrees to facilitate exposure of the left flank; the previously insrted pigtail drain was removed at that stage. Our operative plan consisted of getting access both the left iliac fossa and the left flank palpable collections with a $1.5 \mathrm{~cm}$ incision through which a $12 \mathrm{~mm}$ blunt-tip laparoscopic port would be inserted, allowing the subsequent introdution of a $5 \mathrm{~mm}$ flexible cystoscope, which would enable us to navigate through the abscess cavities with more degrees of freedom compared to the standard laparoscopes, as well as allow lavage of the abscess cavities under vision. As planned, both collections were accessed and a total of 2.5 litres of remaining pus were drained, with another sample sent for culture and antibiotic sensitivites. Thorough lavage with normal saline was perfomed and no obvious communication with the colon was identified during final endoscopic inspetions. At the end of the procedure, one $24 \mathrm{~F}$ silastic drain was inserted in each collection over a guide-wire, which was threaded through the endoscope at the gravity-dependent aspects of the collections.

The patient had an uneventful recovery and there was a marked redution in the collections' size, as seen on the postoperative CT scan (Fig. 3). Of note, all obtained cultures from the abscess cavities deteted Staphylococcus Aureus as the sole pathogen, which was sensitive to flucloxacillin; staining for tuberculosis was negative and also no enteric flora were detected. The consistent absence of gut flora in the reperated fluid clutures, in combination with our intraoperative endoscopic findings, suggested that the collections most likely corresponded to primary psoas abscesses, rather than fistulating abscesses of colonic origin, which was the other differential diagnosis. The patient remained on intravenous antibiotics and both drains were removed once the effluent was macrosopically clear of pus over a consistent period of 72 hours. After consulting our microbiology team, she was discharged with extended course of oral
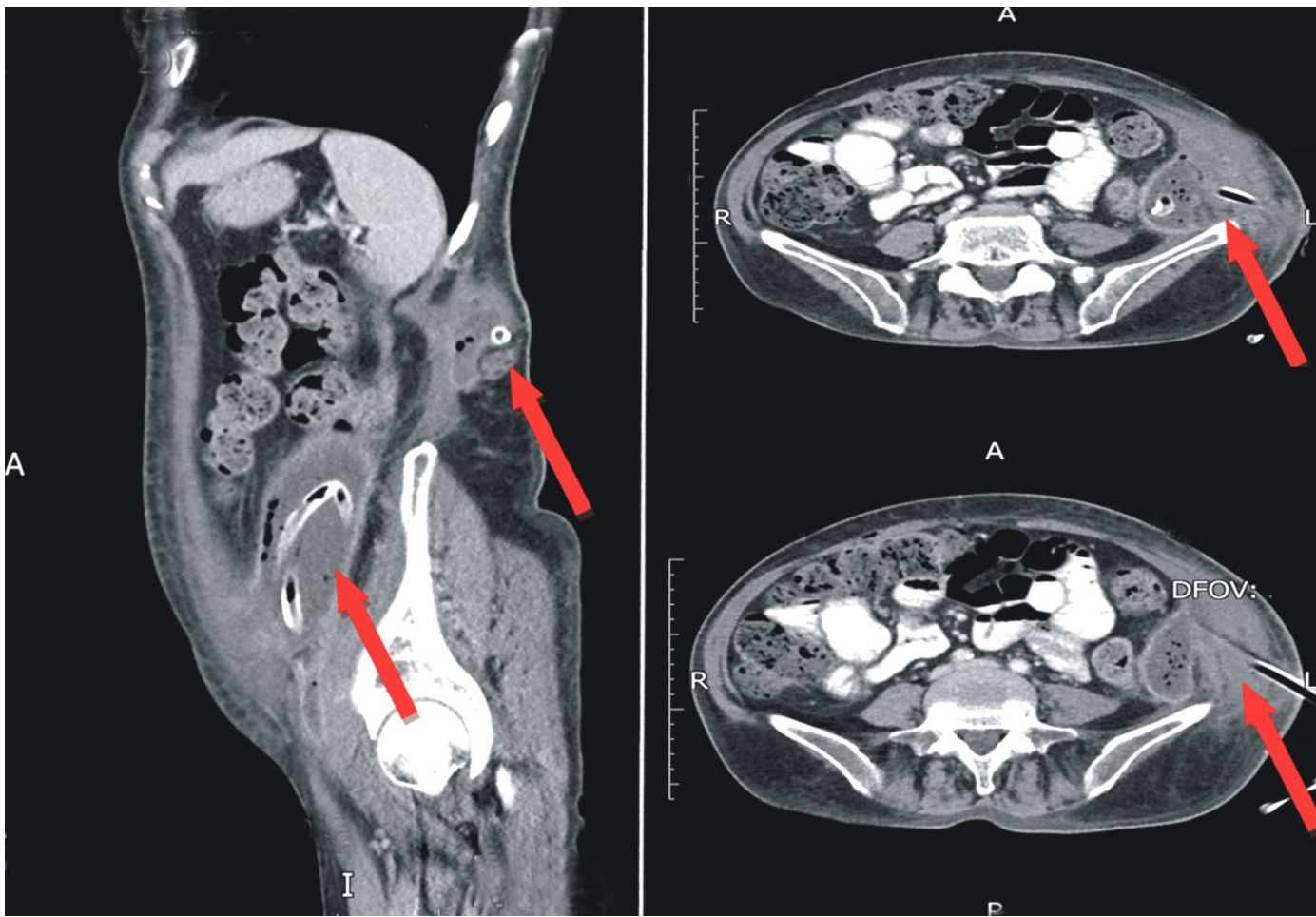

Figure 3. Repeat CT scan after the percutaneous retroperitoneoscopic drainage and large-bore silastic drains (total of 2) placement in the main collections (red arrows) 
flucloxacillin. She also underwent an outpatient follow-up flexible sigmoidoscopy, which revealed the presence of very few scattered divarticulae only, as well as a magnetic resonance imaging (MRI) of her spine, which revealed complete resolution of all the extraperitoneal collections and no other sinister pathology (Fig. 4 ).

\section{Discussion}

Psoas abscesses represent an infrequently encountered clinical entity and their treatment in the majority of cases will be achieved with appropriate antimicrobial treatment, with potential need for drainage by means of interventional radiology, open surgery or, as descibed more recently, with the utilisation of percutaneous videoscopic techniques (7-10). Regarding the latter, the typically used equipment is similar to the standard general laparoscopy kits (ports-trocars, rigid laparoscope), which should be sufficient to address solitary, non-loculated collections. However, in cases like the one we preseneted, we felt that the rigid laparoscope would not enable us to obtain a well-rounded view of the multiple collection cavities to assess for completion of drainage and mainly to ascertain whether these abscesses could be originating from the colon. This thorough inspection would be of paramount importance in the treatment strategy for this patient, as if there was strong suspicion of colonic origin of these extraperitoneal abscesses, the patient would require a colonic resection.

To the best of our knowledge, although the used of flexible endoscopes has been desribed in other retroperitoneoscopic percutaneous procedures, such as pancreatic necrosectomies (11), our case is the first one to describe in detail the successful use of flexible endoscopy in retroperitoneoscopic percutaneous drainage of complex psoas abscesses. The significant benefits of this modified technique in our case were the ability to perform a direct visualisation of the abscess cavities' after the completion of the lavage which, in combination with the consistent results of absence of gut flora from the multiple obtained cultures

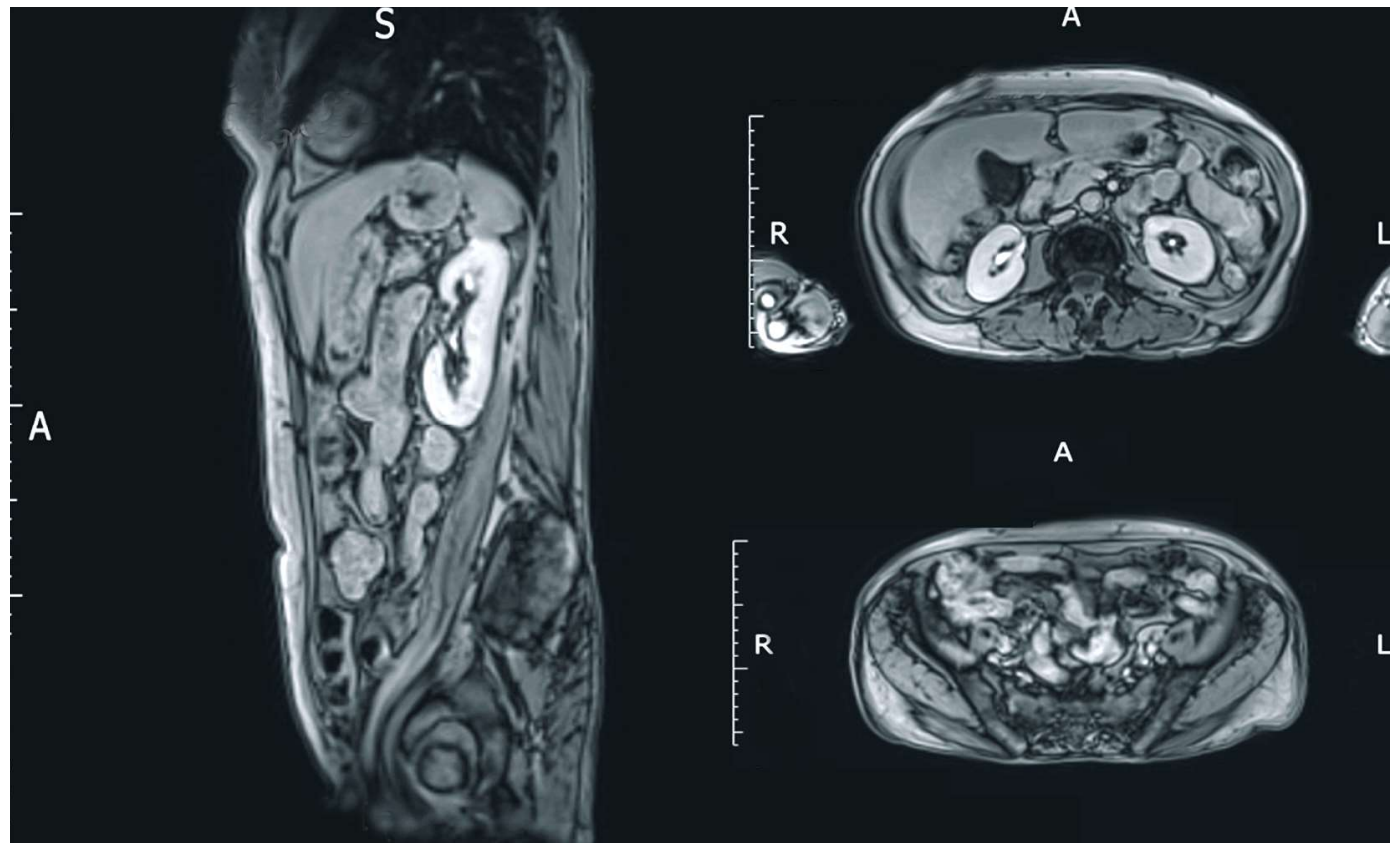

Figure 4. Complete resolution of all extraperitoneal collections in follow-up MRI scan, approximately 3 months after the percutaneous retroperitoneoscopic drainage 
and the follow-up sigmoidoscopy, enabled us to avoid an unnecessary major colonic resection for our patient. In addition, the ability to use a guidewire through the endoscope, which the standard laparoscopes do not offer, allowed us to place appropriately our surgical drains over the guidewire to allow for complete subsequent drainage of the collections in the immediate postoperative period. Finally, as demonstrated in our case, our modified retroperitoneoscopic perutaneous technique could be implemented as a one-stop theraputic procedure, bypassing the need for any intervantional radiology procedures, which are not always available in all hospital settings.

\section{Conclusion}

Summarizing, based on our experience with this case, we would strongly recommend the consideration of use of flexible endoscopes rather than standard laparoscopes in cases of retroperitoneoscopic treatment of complex extraperitoneal collections, particularly in cases of diagnostic uncertainity regarding their primary origin.

\section{Author Contributions}

CS: concept of technique and manuscript, drafting of manuscript. FS, SY \& GJ: literature review and drafting of manusript. AM \& KZ: editing and critical revision of manuscript. All listed authors approve the manuscript at its final form.

\section{Conflict of Interests}

None to be declared by the authors.

\section{Funding}

No funding was required / obtained.

\section{Informed Consent}

Informed written consent for publication and accompanying images was obtained from the patient prior to collecting information and it is available upon request of the Editorial Office

\section{Data Availabilty}

All data generated or analyzed during this study are included in this published article.

\section{References}

1. Chern $\mathrm{CH}$, Hu SC, Kao WF, Tsai J, Yen D, Lee CH, et al. Psoas abscess: Making an early diagnosis in the ED. Am J Emerg Med. 1997;15(1):83-8.

2. Rodrigues J, lyyadurai R, Sathyendra S, Jagannati M, Prabhakar Abhilash KP, Rajan SJ. Clinical presentation, etiology, management, and outcomes of iliopsoas abscess from a tertiary care center in South India. J Family Med Prim Care. 2017;6(4):836-839.

3. Tabrizian P, Nguyen SQ, Greenstein A, Rajhbeharrysingh U, Divino CM. Management and treatment of iliopsoas abscess. Arch Surg. 2009;144(10):946-9.

4. Nakamura T, Morimoto T, Katsube K, Yamamori $Y$, Mashino J, Kikuchi K. Clinical characteristics of pyogenic spondylitis and psoas abscess at a tertiary care hospital: a retrospective cohort study. J Orthop Surg Res. 2018;13(1):302.

5. Atkin G, Qurashi K, Isla A. Laparoscopic drainage of bilateral tuberculous psoas abscesses. Surg Laparosc Endosc Percutan Tech. 2005;15(6):380-2.

6. Büyükbebeci 0, Seçkiner I, Karsı B, Karakurum G, Başkonuş I, Bilge 0 , et al. Retroperitoneoscopic drainage of complicated psoas abscesses in patients with tuberculous lumbar spondylitis. Eur Spine J. 2012;21(3):470-3. Epub 2011 Oct 21.

7. Katara AN, Shah RS, Bhandarkar DS, Unadkat RJ. Retroperitoneoscopic drainage of a psoas abscess. J Pediatr Surg. 2004;39(9): e4-5.

8. Cantasdemir M, Kara B, Cebi D, Selcuk ND, Numan F. Computed tomography-guided percutaneous catheter drainage of primary and secondary iliopsoas abscesses. Clin Radiol. 2003;58(10):811-5.

9. Joob B, Wiwanitkit V. Retroperitoneoscopic drainage of bilateral psoas abscesses. Asian J Endosc Surg. 2014:7(4):345

10. Chang Hwa Hong, Yong Cheol Hong, Sang Ho Bae, Myoung Won Son 2, Sung Hun Won 3, Aeli Ryu 4, et al. Laparoscopic drainage as a minimally invasive treatment for a psoas abscess: A singlecenter case series and literature review. Medicine (Baltimore). 2020;99(14):e19640

11. Moyer MT, Walsh LT, Manzo CE, Loloi J, Burdette A, Mathew A. Percutaneous debridement and washout of walled-off abdominal abscess and necrosis by the use offlexible endoscopy: an attractive clinical option when transluminal approaches are unsafe or not possible. VideoGIE. 2019;4(8):389-393. eCollection 2019 Aug. 